\title{
Working
}

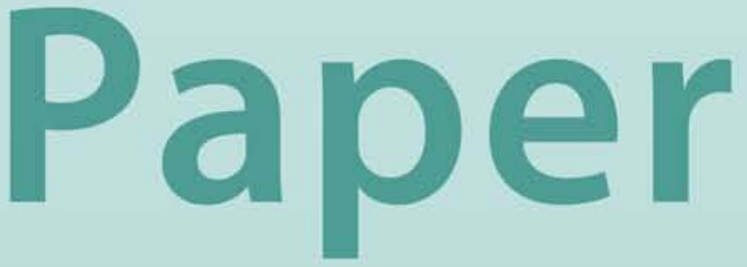




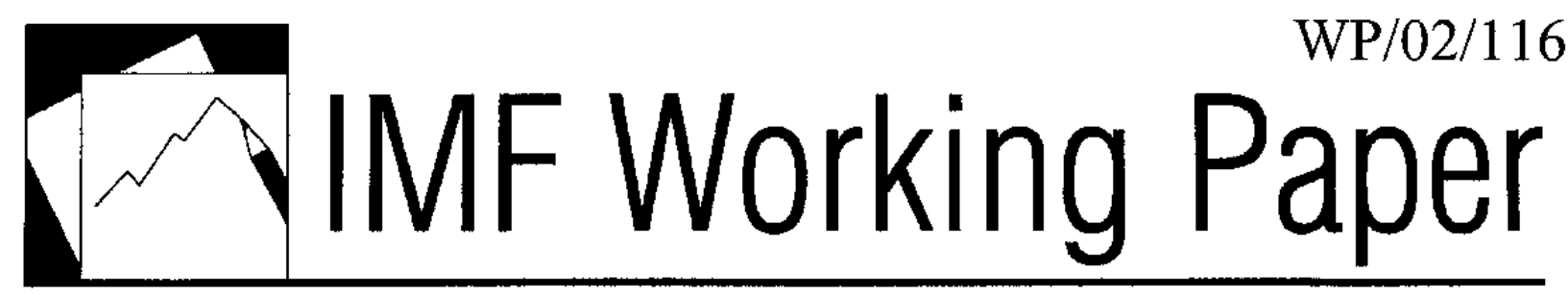

\title{
Assessing Monthly Progress Toward Annual Fiscal Revenue Targets
}

\author{
Daniel Kanda
}




\title{
IMF Working Paper
}

Asia and Pacific Department

\section{Assessing Monthly Progress Toward Annual Fiscal Revenue Targets}

\author{
Prepared by Daniel Kanda ${ }^{1}$ \\ Authorized for distribution by Kalpana Kochhar
}

July 2002

\begin{abstract}
The views expressed in this Working Paper are those of the author(s) and do not necessarily represent those of the IMF or IMF policy. Working Papers describe research in progress by the author(s) and are published to elicit comments and to further debate.
\end{abstract}

A simple statistical methodology is developed to help evaluate monthly progress toward an annual fiscal revenue target, and the applicability of the methodology to both developing and industrial countries is demonstrated using data for Sri Lanka and the United States.

JEL Classification Numbers: C12, C51, C53, H61

Keywords: Sri Lanka; United States; fiscal; revenue; hypothesis testing

Author's E-Mail Address: dkanda@imf.org

\footnotetext{
${ }^{1}$ I am thankful to Jeremy Carter, Emmanuel Kumah, Christopher Towe, Kalpana Kochhar, Paula De Masi, Yougesh Khatri, and Katherine Baer for their valuable comments.
} 


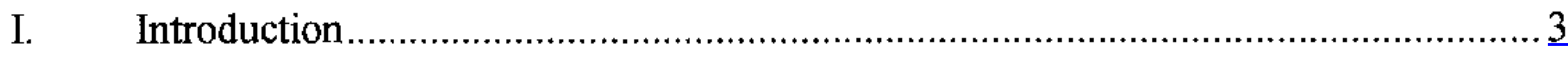

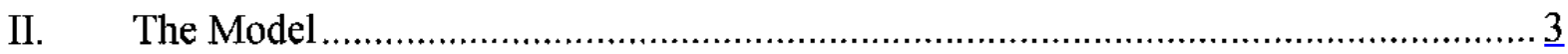

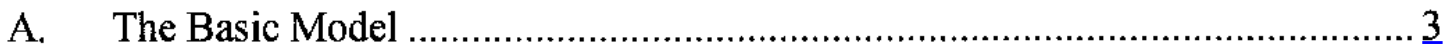

B. Intra-Year Policy Changes.......................................................................

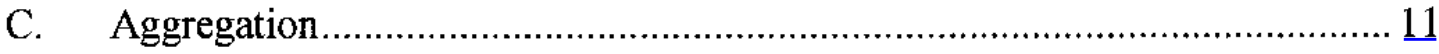

III. Empirical Results for Sri Lanka .................................................................

A. Evaluating the July Budget Estimates..................................................... 15

B. Evaluating the October Budget Estimates .................................................19

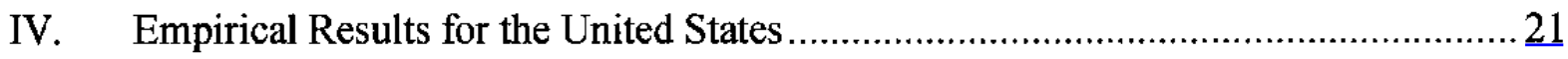

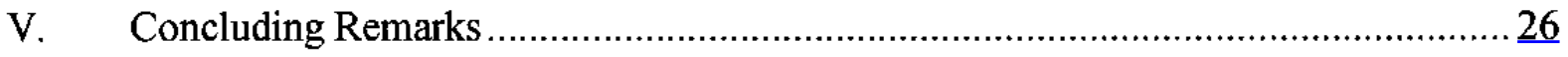

Appendix. Conditions for Exact Aggregation …………............................................. 27

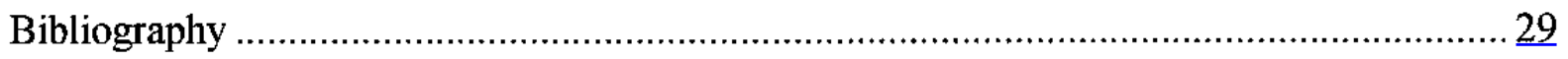

Tables

Table 1. Sri Lanka: Budget Revenue Estimates and Outturn in 2000 ............................. 13

Table 2. United States: Budget Receipts Estimates and Outturn in FY2000 ……...............21

Figures

Figure 1. Sri Lanka: Evaluation of July Budget Estimates ............................................... 16

Figure 2. Sri Lanka: Evaluation of October Budget Estimates ........................................... 20

Figure 3. United States: Evaluation of Budget Estimates ................................................23 


\section{INTRODUCTION}

The purpose of this paper is to develop a statistical methodology for evaluating the likelihood of meeting annual fiscal revenue targets, given partial-year monthly data.

Notwithstanding the steady increase in the availability of monthly and quarterly data for many macroeconomic variables, most policy discussions and actions are still couched in terms of annual targets. This raises the obvious question of how best to use available monthly or quarterly data to judge progress toward annual targets. For example, given part-year monthly data on government revenue, or exports, or GDP, we might want to know whether the data indicate that government is on track to meet its annual revenue target, or that the annual export or GDP target would be met. This could then be the basis for deciding whether corrective policy actions are required.

Currently, a simple "eyeball" method is often used in such evaluations. This usually involves comparing monthly outturns to what would be expected if the annual target were generated in a uniform fashion. Where the monthly outturn falls well below this expected level, this is considered evidence that the annual target is likely to be missed. This methodology has two problems however; first, the determination of the point at which a monthly outturn could be considered too far below expectations is subjective; second, as a result of seasonal variation and other factors, the share of annual revenue collected in any particular month may systematically deviate from what would be expected if revenue were collected in a uniform fashion, thus increasing the potential for misleading conclusions. Thus there is a need for a simple framework which incorporates all the above intuitive considerations and permits statistically rigorous inference.

The statistical framework developed in this paper allows us to use data from previous years to help answer the above questions, and its application is illustrated using Sri Lankan and U.S. fiscal revenue data. As we shall see, the methodology can be easily adapted to evaluate progress toward other key macroeconomic and policy targets-it is potentially applicable wherever we have an annual target and monthly outturns which are expected to sum up to the annual target. Another advantage of the framework is that it is very simple to implement in any spreadsheet and does not require sophisticated knowledge of statistics - the empirical results in this paper were generated using Microsoft Excel.

\section{THE MODEL}

\section{A. The Basic Model}

Let $x_{i t}, i=1,2, \ldots 12, t=1,2, \ldots N$ represent revenue in month $i$ of year $t$. We assume that $x_{i t}$ depends deterministically on a variable $T_{t}$ (discussed below) and the month of the year, plus a random element, and that this relationship can be written as

$$
x_{i t}=x_{i}\left(T_{t}\right)+\varepsilon_{i t},
$$


where $\varepsilon_{i t}$ is assumed to be normally distributed $N\left(0, \sigma_{i t}^{2}\right)$. Thus $x_{i t} \sim N\left(x_{i}\left(T_{t}\right), \sigma_{i t}^{2}\right)$, where $x_{i}\left(T_{t}\right)$ represents expected revenue, given $T_{t}$ and the month of year. Note that $x_{i}($.$) is$ assumed to be time-independent, which is the case if the pattern of monthly tax collections is stable over the years. ${ }^{2}$ On the other hand, it is reasonable to expect that $\sigma_{i t}^{2}$ would vary directly with the level of annual revenue.

$T_{t}$ is itself assumed to be a function of a number of variables, including the tax rate, the tax base, national income, and the efficiency of tax administration. However, for the purposes of this paper it is not necessary to explicitly model this function. For any particular year $t$, summing monthly revenue over 12 months gives the expected total revenue for the year, denoted as

$$
X\left(T_{t}\right)=E\left(\sum_{i=1}^{12} x_{i i}\right)=\sum_{i=1}^{12} x_{i}\left(T_{t}\right)
$$

We also assume that total annual revenue is solely determined by $T_{t}$. This implies that conditional on $T_{t}$ the total annual revenue is non-random, so that expected and actual total annual revenue are identical. Hence we have the following restriction:

$$
\sum_{i=1}^{12} \varepsilon_{i t}=0
$$

Thus, in any particular year and given $T_{t}$, the $\varepsilon_{i t}$ may vary independently only in the first 11 months, with the twelfth month being determined by

$$
\varepsilon_{12 t}=-\sum_{i=1}^{11} \varepsilon_{i t}
$$

We therefore focus on the first 11 months. This does not imply any loss of generality, as all uncertainty disappears once data on the outturn for the $12^{\text {th }}$ month is received - it is then readily apparent whether annual revenue was on target or not.

In assessing revenue performance as of a particular month, we are generally interested in total revenue generated up to that month. In line with this, let

$$
y_{j t}=\sum_{i=1}^{j} x_{i t}
$$

\footnotetext{
${ }^{2}$ The model is easily extended to deal with the case where the pattern of monthly tax revenues is not fixed, but has a stable distribution-see Method 1 below.
} 
where $j \leq 11$. Then $y_{j t}$ is also normally distributed, and

$$
\begin{array}{r}
E\left(y_{j t}\right)=\sum_{i=1}^{j} E\left(x_{i t}\right)=\sum_{i=1}^{j} x_{i}\left(T_{t}\right) \\
\operatorname{Var}\left(y_{j t}\right)=\sum_{i=1}^{j} \sigma_{i t}^{2}+2 \sum_{1 \leq i<k \leq j} \sum_{j} \operatorname{cov}\left(\varepsilon_{i t}, \varepsilon_{k t}\right)
\end{array}
$$

Now suppose that at the beginning of year $t$, the authorities estimate that $T_{t}=T^{*}$ and therefore that expected total revenue is given by

$$
X^{*}=X\left(T^{*}\right)
$$

Given a partial-year revenue outturn up to month $j$, our aim is to test whether this outturn is consistent with the authorities estimate of total revenue. We thus formulate a test as follows:

Null hypothesis

$$
\begin{aligned}
& H_{0}: X\left(T_{t}\right)=X^{*} \\
& H_{a}: X\left(T_{t}\right) \neq X^{*}
\end{aligned}
$$

Alternative hypothesis

The test statistic is then calculated as follows:

Let $P_{j t}=\frac{y_{j t}}{X^{*}}$. Then $P_{j t}$ represents the share of expected total revenue collected as of month $j$. As $X^{*}$ is fixed (not a random variable) under the null hypothesis, it is easily determined that $P_{j t}$ is also normally distributed, with mean and variance given by

$$
\begin{aligned}
& E\left(P_{j t}\right)=\frac{\sum_{i=1}^{j} x_{i}\left(T_{t}\right)}{X^{*}} \\
& \operatorname{Var}\left(P_{j t}\right)=\frac{\operatorname{Var}\left(y_{j t}\right)}{\left(X^{*}\right)^{2}}
\end{aligned}
$$

Although a test statistic could be constructed directly based on $P_{j t}$, it is informative to also compare $P_{j t}$ to the revenue that would have been generated by period $j$ if revenue were collected in a uniform fashion. Such a comparison casts light on the extent of over performance or underperformance of revenue generation. 
Suppose annual revenue were collected in 12 equal monthly installments. In that case, revenue collected in period $i$ would be given by $x_{i t}^{u}=\frac{X^{*}}{12}$, cumulative revenue collected after $j$ periods would be $y_{j t}^{u}=\frac{j\left(X^{*}\right)}{12}$, and the share of expected annual revenue collected after $j$ periods would be $P_{j t}^{u}=\frac{j}{12}$. Thus the difference $P_{j t}-P_{j t}^{u}$ can be used as a measure of performance in revenue collection: where $P_{j t}-P_{j t}^{u}>0$, revenue is being collected at a faster pace than would be expected if revenue collection were evenly spread throughout the year, and can therefore be said to be overperforming. The converse also holds. Thus we define the following variable:

Let

$$
U_{j t}=P_{j t}-P_{j t}^{u}=\frac{y_{j t}}{X^{*}}-\frac{j}{12}
$$

Then under the null hypothesis $U_{j t}$ is normally distributed with mean and variance given by

$$
\begin{gathered}
E\left(U_{j t}\right)=\frac{\sum_{i=1}^{j} x_{i}\left(T_{t}\right)}{X^{*}}-\frac{j}{12} \\
\operatorname{Var}\left(U_{j t}\right)=\operatorname{Var}\left(P_{j t}\right)=\frac{\operatorname{Var}\left(y_{j t}\right)}{\left(X^{*}\right)^{2}}
\end{gathered}
$$

As $E\left(U_{j z}\right)$ and $\operatorname{Var}\left(U_{j t}\right)$ are unknown, it is necessary to make a few simplifying assumptions, designed to permit the use of sample estimators. In particular, let expected monthly revenue, $x_{i}\left(T_{t}\right)$, be a linear function of expected annual revenue $X(T)$, such that

$$
x_{i}\left(T_{t}\right)=\alpha_{i} X\left(T_{t}\right)
$$

where $\alpha_{i}>0$, and

$$
\sum_{i=1}^{12} \alpha_{i}=1
$$

Thus, in effect, the $\alpha_{i}$ can be thought of as reflecting monthly seasonal variation. Then under the null hypothesis, 


$$
E\left(U_{j t}\right)=\frac{X\left(T^{*}\right) \sum_{i=1}^{j} \alpha_{i}}{X\left(T^{*}\right)}-\frac{j}{12}=\sum_{i=1}^{j} \alpha_{i}-\frac{j}{12}=\mu_{j}
$$

Clearly, $\mu_{j}$ is time invariant. Also, we allow for the influence of the level of revenue on the variance/covariance terms by adopting the following simple functional forms:

Let

$$
\begin{gathered}
\sigma_{i t}^{2}=\sigma_{i}^{2} X\left(T_{t}\right)^{2} \\
\operatorname{cov}\left(\varepsilon_{i t}, \varepsilon_{k t}\right)=\sigma_{i k} X\left(T_{t}\right)^{2}
\end{gathered}
$$

where, $\sigma_{i}$ and $\sigma_{i k}$ are constants. Then under the null hypothesis,

$$
\operatorname{Var}\left(U_{j t}\right)=\frac{X\left(T^{*}\right)^{2} \sum_{i=1}^{j} \sigma_{i}^{2}+2 X\left(T^{*}\right)^{2} \sum_{1 \leq i<k \leq j} \sum_{i k}}{X\left(T^{*}\right)^{2}}=\sum_{i=1}^{j} \sigma_{i}^{2}+2 \sum_{1 \leq i<k \leq j} \sum_{i k}=\varsigma_{j}^{2}
$$

Evidently, $\varsigma_{j}^{2}$ is also time invariant. We can then calculate estimates for $\mu_{j}$ and $\varsigma_{j}^{2}$ as follows: for any given month $j$ we have a random sample of $U_{j t}$ of size $N$, covering the previous years for which we have complete data, all drawn from the same population- - the normal distribution $N\left(\mu_{j}, \varsigma_{j}^{2}\right)$. Thus we can calculate estimates for $\varsigma_{j}^{2}$ and $\mu_{j}$ in the standard manner using the following estimators.

$$
\begin{gathered}
\bar{\mu}_{j}=\frac{\sum_{t=1}^{N} U_{j t}}{N} \\
\hat{\varsigma}_{j}^{2}=\frac{\sum_{i=1}^{N}\left(U_{j t}-\bar{\mu}_{j}\right)^{2}}{N-1}
\end{gathered}
$$

It is well known that given a random sample drawn from the same normal population $\hat{\zeta}_{j}^{2}$ and $\bar{\mu}_{j}$ are independent.

Suppose now that we are currently in year $t=N+1$, and have only partial-year data $U_{j N+1}$ which we wish to evaluate. Under the null hypothesis $U_{j N+1} \sim N\left(\mu_{j}, \varsigma_{j}^{2}\right)$, and $\bar{\mu}_{j} \sim N\left(\mu_{j}, \frac{\varsigma_{j}^{2}}{N}\right)$. Moreover, $U_{j N+1}$ is independent from $\bar{\mu}_{j}$ and $\hat{\zeta}_{j}^{2}$, as it is an independent draw from a different time period than covered by these sample estimators. Thus we have 
$U_{j N+1}-\bar{\mu}_{j} \sim N\left(0, \frac{\varsigma_{j}^{2}(N+1)}{N}\right)$. It is also a standard result that $\frac{\sum_{t=1}^{N}\left(U_{j t}-\bar{\mu}_{j}\right)^{2}}{\varsigma_{j}^{2}} \sim \chi_{N-1}^{2}$ (see, for example Roussas (1997), pp 354). Hence the following result follows (see, for example Roussas (1997), pp 229): ${ }^{3}$

$$
\hat{W}_{j}=\frac{\left(U_{j N+1}-\bar{\mu}_{j}\right)}{\hat{\varsigma}_{j}} \sqrt{\frac{N}{N+1}} \sim t_{N-1} .
$$

We therefore use $\hat{W}_{j}$ as our test statistic. One advantage of this test is that it is an exact test which is valid even with small samples, given the normality assumption for the $\varepsilon_{i t}$. The $t$ distribution automatically corrects for the fact that the standard deviation is estimated from a small sample by an adjustment of the degrees of freedom. On the other hand, the test may yield misleading results if the $\varepsilon_{i t}$ are far from normally distributed.

\section{B. Intra-Year Policy Changes}

Inter-year policy changes - announced at the beginning of the year and affecting all months of the year-are automatically dealt with in the above model. For example, a policy change at the beginning of the year, such as a tax rate change or a change in the tax base, would affect the annual target $X\left(T_{t}\right)$, but would not affect the distribution of $P_{j t}, U_{j t}$, or $\hat{W}_{j}$. On the other hand, intra-year policy changes clearly have an impact on the pattern of tax collections within the year. ${ }^{4}$ For example, an increase in the tax rate at mid-year would cause expected monthly revenues to be larger in the second half of the year than they would otherwise be, which would introduce a source of bias to the test. ${ }^{5}$ There are two possible ways to deal with this problem, which we outline below:

\section{Method 1}

This method is most useful in cases where intra-year changes are quite frequent, and are typically not associated with very large changes in revenue. It is also applicable when we do not have complete information about all intra-year policy changes in the years for which we have data. Here we amend the model as follows:

\footnotetext{
${ }^{3}$ The basic result is that given any two independent random variables $z \sim N(0,1)$ and $q \sim \chi_{r}^{2}$, the random variable $t=z / \sqrt{q / r}$ has a $t$ distribution with $r$ degrees of freedom.

${ }^{4}$ Policies announced at the beginning of the year, but which take effect during the year, are equivalent to intrayear policy changes.

${ }^{5}$ Another possibility is where a policy change at a point in time permanently changes the monthly pattern of tax collections. This is equivalent to a structural break, in which case the simplest option would be to use only data for the years following the break. As the test is valid in small samples, this should not be a problem.
} 
Assume that the seasonal factors in a particular month are not fixed, but rather can be influenced by various intra-year policy actions - which occur in a random fashion from year to year. In particular, the model governing $x_{i t}$ is now modified as follows: let

$$
x_{i t}=\alpha_{i t} X\left(T_{t}\right)+\varepsilon_{i t},
$$

where $\alpha_{i t}$ is distributed as $N\left(\alpha_{i}, \delta_{i}^{2}\right), \operatorname{cov}\left(\alpha_{i t}, \alpha_{k t}\right)=\delta_{i k}$, and $\alpha_{i t}$ and $\varepsilon_{i t}$ are independent. Then summing equation (23) over the 12 months of the year, we find that $\sum_{i=1}^{12} \alpha_{i t}=1$, thus implying that for a given $T_{t}, \alpha_{12 t}$ does not independently vary, but is determined as $\alpha_{12 t}=1-\sum_{i=1}^{11} \alpha_{i t}$. As before, this is not a serious problem, since we focus on the first 11 months of the year. For a given $T_{t}, x_{i t}$ is normally distributed with the following moments:

$$
\begin{gathered}
E\left(x_{i t}\right)=X\left(T_{t}\right) E\left(\alpha_{i t}\right)+E\left(\varepsilon_{i t}\right)=\alpha_{i} X\left(T_{t}\right) \\
\operatorname{Var}\left(x_{i t}\right)=\delta_{i}^{2}\left(X\left(T_{t}\right)\right)^{2}+\sigma_{i}^{2}\left(X\left(T_{t}\right)\right)^{2}=\left(X\left(T_{t}\right)\right)^{2}\left(\delta_{i}^{2}+\sigma_{i}^{2}\right)
\end{gathered}
$$

Similarly, $y_{j t}$ is also normally distributed with the following moments:

$$
\begin{gathered}
E\left(y_{j t}\right)=\sum_{i=1}^{j} E\left(x_{i t}\right)=\sum_{i=1}^{j} \alpha_{i} X\left(T_{t}\right) \\
\operatorname{Var}\left(y_{j t}\right)=\left(X\left(T_{t}\right)\right)^{2} \sum_{i=1}^{j}\left(\sigma_{i}^{2}+\delta_{i}^{2}\right)+2 \sum_{1 \leq i<k \leq j} \sum_{j} \operatorname{cov}\left(\varepsilon_{i t}, \varepsilon_{k t}\right)+2\left(X\left(T_{t}\right)\right)^{2} \sum_{1 \leq i<k \leq j} \sum_{j} \operatorname{cov}\left(\alpha_{i t}, \alpha_{k t}\right)
\end{gathered}
$$

Then under the null hypothesis (same as above)

$$
\begin{gathered}
E\left(U_{j t}\right)=\frac{X\left(T^{*}\right) \sum_{i=1}^{j} \alpha_{i}}{X\left(T^{*}\right)}-\frac{j}{12}=\sum_{i=1}^{j} \alpha_{i}-\frac{j}{12}=\mu_{j} \\
\operatorname{Var}\left(U_{j t}\right)=\frac{\operatorname{var}\left(y_{j t}\right)}{X\left(T^{*}\right)^{2}}=\sum_{i=1}^{j}\left(\sigma_{i}^{2}+\delta_{i}^{2}\right)+2 \sum_{1 \leq i<k \leq j} \sum \sigma_{i k}+2 \sum_{1 \leq i<k \leq j} \sum_{i k} \delta_{i}=\Omega_{j}^{2}
\end{gathered}
$$

Comparing $\Omega_{j}^{2}$ and $\varsigma_{j}^{2}$, we see that the main impact of this modification of the model is to increase the sources of variability of the test statistic. This makes it clear that frequent large 
intra-year policy changes would increase the size of the acceptance region of the test, and thereby lower the power of the test.

The actual implementation of the test is unchanged, as the sample estimator for $\Omega_{j}^{2}$ is the same as that for $\varsigma_{j}^{2}$ (i.e. the sample variance for $U_{j t}$ ). Thus, in effect, the test is robust to intra-year policy changes which are not too large.

\section{Method 2}

In cases where intra-year policy changes are large and infrequent, and we have exact details of all such changes throughout the sample period, we can eliminate the effect of a policy change as follows:

Suppose that a policy change is announced in month $l$, where $l \leq 11$, such that expected tax revenue from month $l$ onward is changed by a factor $\beta$. Then we have the following:

For $i=1, \ldots l-1$,

For $i=l, \ldots 12$

$$
x_{i t}=x_{i}\left(T^{*}\right)+\varepsilon_{i t}=\alpha_{i} X\left(T^{*}\right)+\varepsilon_{i t}
$$

$$
x_{i t}=\beta x_{i}\left(T^{*}\right)+v_{i t}=\alpha_{i} \beta X\left(T^{*}\right)+v_{i t}
$$

where $v_{i t}=\beta \varepsilon_{i t}$. Notice that we do not differentiate between policy changes in the form of a change in the tax rate or a change in the tax base, as we are only concerned with the impact on revenue. For the months preceding month $l$, hypothesis tests can be conducted in the same manner as before. However for months $j \geq l$ we proceed as follows:

Define

$$
\widetilde{P}_{j t}=\sum_{i=1}^{l-1} \frac{x_{i t}}{X\left(T^{*}\right)}+\sum_{i=l}^{j} \frac{x_{i t}}{\beta X\left(T^{*}\right)}
$$

then $\widetilde{P}_{j t}$ corrects for the impact of the policy change on the monthly pattern of tax collections. Thus if there is information to determine $\beta$, in every year where intra-year policy changes took place, we can eliminate the distortions created in the monthly patterns of tax collections.

$$
E\left(\widetilde{P}_{j t}\right)=\sum_{i=1}^{l-1} \frac{x_{i}\left(T^{*}\right)}{X\left(T^{*}\right)}+\sum_{i=l}^{j} \frac{\beta x_{i}\left(T^{*}\right)}{\beta X\left(T^{*}\right)}=\sum_{i=1}^{j} \frac{x\left(T^{*}\right)}{X\left(T^{*}\right)}=E\left(P_{j t}\right)
$$

and

$$
\operatorname{Var}\left(\widetilde{P}_{j t}\right)=\sum_{i=1}^{t-1} \frac{\sigma_{i t}^{2}}{\left(X\left(T^{*}\right)\right)^{2}}+\sum_{i=i}^{j} \frac{\sigma_{i t}^{2}}{\left(X\left(T^{*}\right)\right)^{2}}+2 \sum_{i=1}^{i-1} \sum_{k<i} \frac{\operatorname{cov}\left(\varepsilon_{i t}, \varepsilon_{k t}\right)}{\left(X\left(T^{*}\right)\right)^{2}}+2 \sum_{i=l}^{j} \sum_{k<i} \frac{\operatorname{cov}\left(v_{i t}, \varepsilon_{k t}\right)}{\beta\left(X\left(T^{*}\right)\right)^{2}}+2 \sum_{i=l}^{j} \sum_{l \leq k<i} \frac{\operatorname{cov}\left(v_{i t}, v_{k t}\right)}{\beta^{2}\left(X\left(T^{*}\right)\right)^{2}}
$$


Given that $\operatorname{cov}\left(v_{i t}, \varepsilon_{k t}\right)=\beta \operatorname{cov}\left(\varepsilon_{i t}, \varepsilon_{k t}\right)$, and $\operatorname{cov}\left(v_{i t}, v_{k t}\right)=\beta^{2} \operatorname{cov}\left(\varepsilon_{i t}, \varepsilon_{k t}\right)$, the above expression reduces to

$$
\operatorname{Var}\left(\widetilde{P}_{j t}\right)=\sum_{i=1}^{j} \frac{\sigma_{i t}^{2}}{\left(X\left(T^{*}\right)\right)^{2}}+2 \sum_{1 \leq k<i}^{j} \sum \frac{\operatorname{cov}\left(\varepsilon_{i t}, \varepsilon_{k t}\right)}{\left(X\left(T^{*}\right)\right)^{2}}=\varsigma_{j}^{2}
$$

As $\widetilde{P}_{j t}$ is also normally distributed, it is clear that is has the same distribution as $P_{j t}$. Thus we can construct $\widetilde{U}_{j t}=\widetilde{P}_{j t}-P_{j t}^{u}$ and define:

$$
\widetilde{W}_{j}=\frac{\left(\widetilde{U}_{j N+1}-\bar{\mu}_{j}\right)}{\hat{\zeta}_{j}} \sqrt{\frac{N}{N+1}}
$$

as before, $\widetilde{W}_{j} \sim t_{N-1}$.

We can readily extend this adjustment to account for more than one policy change in a year. To illustrate, suppose that subsequent to period $l$, another policy change is announced in period $m$ such that revenue from that month onward is changed by a factor $\gamma$. Then we have:

For $i=1, \ldots l-1$,

$$
x_{i t}=x_{i}\left(T^{*}\right)+\varepsilon_{i t}=\alpha_{i} X\left(T^{*}\right)+\varepsilon_{i t}
$$

For $i=l, \ldots m-1$

$$
x_{i t}=\beta x_{i}\left(T^{*}\right)+v_{i t}=\alpha_{i} \beta X\left(T^{*}\right)+v_{i t}
$$

For $i=m, \ldots 12$

$$
x_{i t}=\beta \gamma x_{i}\left(T^{*}\right)+\omega_{i t}=\alpha_{i} \beta \gamma X\left(T^{*}\right)+\omega_{i t}
$$

where $\omega_{i t}=\beta \gamma \varepsilon_{i t}$.

We can then define

$$
\hat{P}_{j t}=\sum_{i=1}^{l-1} \frac{x_{i t}}{X\left(T^{*}\right)}+\sum_{i=l}^{m-1} \frac{x_{i t}}{\beta X\left(T^{*}\right)}+\sum_{i=m}^{j} \frac{x_{i t}}{\beta \gamma X\left(T^{*}\right)}
$$

and it can be readily shown that $\hat{P}_{j t}$ will also have distribution $N\left(\mu_{j}, \varsigma_{j}^{2}\right)$.

\section{Aggregation}

Although tests on individual tax types give us information about the performance of the tax in question, we are often also interested in whether total revenue from all taxes is on target. This is because it is possible for total revenue to be broadly on target even though some particular tax is underperforming; for example, another tax could overperform, or the underperforming tax may not be a very important source of revenue. To evaluate total 
revenue, it is natural to find out what conditions-if any-would permit the derivation of an aggregate version of the model. If we index tax-type by $q$ where $q=1, \ldots Q$ we can restate the basic model as

$$
x_{q i t}=\alpha_{q i} X_{q}\left(T_{q t}\right)+\varepsilon_{q i t}
$$

where $\varepsilon_{q i t}$ is distributed $N\left(0, \sigma_{q i t}^{2}\right), \sigma_{q i t}^{2}=\sigma_{q i}^{2} X_{q}\left(T_{q t}\right)^{2}$ and $\operatorname{cov}\left(\varepsilon_{q i t}, \varepsilon_{q k t}\right)=\sigma_{q i k} X_{q}\left(T_{q t}\right)^{2}$. Then aggregate revenue in a particular month would be given by

$$
Z_{i t}=\sum_{q=1}^{Q} x_{q i t}
$$

and total revenue for the year would be given by

$$
T R_{t}=\sum_{q=1}^{Q} X_{q}\left(T_{q t}\right)
$$

We are interested in the following hypothesis:

Null hypothesis

Alternative hypothesis

$$
\begin{aligned}
& H_{0}: T R_{t}=T R^{*} \\
& H_{a}: T R_{t} \neq T R^{*}
\end{aligned}
$$

To perform the test in an analogous fashion as for individual tax types, we need to establish the conditions under which the model for which the data generating process for $Z_{i t}$ is a special case can be written as

$$
Z_{i t}=\delta_{i} T R_{t}+v_{i t}
$$

where $v_{i t}$ is distributed $N\left(0, \psi_{i t}^{2}\right), \psi_{i t}^{2}=\psi_{i}^{2} T R_{t}^{2}$, and $\operatorname{cov}\left(v_{i t}, v_{k t}\right)=\psi_{i k} T R_{t}^{2}$. It is shown in the appendix that the following conditions are sufficient for aggregation to hold exactly.

1. $X_{q}\left(T_{q t}\right)=\tau_{q} T R_{t}$ where $\tau_{q}$ are constant and $\sum_{q=1}^{Q} \tau_{q}=1$, for all $t$. In other words, the shares of various taxes in total revenue are constant.

2. $\operatorname{cov}\left(\varepsilon_{q i t}, \varepsilon_{s k t}\right)=0$ for all $q \neq s$. In other words, error terms from different tax types are independent.

While condition 1 is not expected to hold exactly in most countries, further investigation and some limited numerical simulations suggest that the model in equation (44) provides a good 
approximation to the data generating process for $Z_{i t}$, so far as the tax shares do not vary sharply from year to year. Moreover, the approximation is better if:

1a. $\alpha_{q i}$ do not vary greatly across the different tax types.

2a. $\sigma_{q i}^{2}$ do not vary greatly across the different tax types.

3a. $\sigma_{\text {qik }}$ do not vary greatly across the different tax types.

From this point onward, we will abstract from aggregation issues, and simply assume that conditions 1 and 2 hold sufficiently well in Sri Lanka and the United States.

\section{EMPIRICAL RESULTS FOR SRI LANKA}

To illustrate the test we first evaluate the progress of revenue generation in Sri Lanka in 2000 . As it turns out, 2000 was a year in which many interesting issues came up.

- There were a number of intra-year policy changes, including an increase in the National Security Levy (NSL) rate from 5.5 percent to 6.5 percent in May, increases in excise taxes on cigarettes and liquor in May, a reduction in excise duty on petroleum products in November, and a number of changes to import duties.

- Revenue estimates were revised four times during the year-in June, July, September, and October.

- There was a significant shortfall in revenue for the year as a whole, notwithstanding the revisions in revenue estimates.

Table 1. Sri Lanka: Budget Revenue Estimates and Outturn in 2000

\begin{tabular}{|c|c|c|c|c|c|c|}
\hline \multicolumn{7}{|c|}{ millions of Sri Lanka rupees } \\
\hline & Original budget & Revised June 6 th $1 /$ & Revised July 15th & Revised Sept 8th & Revised Oct 31st & Outlun \\
\hline Total revemue & 233,974 & 231,172 & 233,866 & 233,933 & 231,933 & 211,281 \\
\hline Tax revenue & 201,765 & 199,713 & 202,407 & 202,474 & 200,474 & 182,392 \\
\hline Income tax & 29,229 & 30,141 & 30,141 & 30,208 & 28,208 & 27,457 \\
\hline Turnover taxes/GST $2 /$ & 53,295 & 48,430 & 48,944 & 48,944 & 48,944 & 45,600 \\
\hline Excises & 46,552 & 47,377 & 47,977 & 47,977 & 47,977 & 42,655 \\
\hline National Security Levy & 35,340 & 35,340 & 36,260 & 36,260 & 36,260 & 33,539 \\
\hline Import duty & 26,874 & 27.950 & 28,610 & 28,610 & 28,610 & 23,970 \\
\hline Other $3 /$ & 10,475 & 10,475 & 10,475 & 10,475 & 10,475 & 9,170 \\
\hline Nontax revenue & 32,209 & $3 I, 459$ & 31,459 & 31,459 & 31,459 & 28,890 \\
\hline \multicolumn{7}{|c|}{ Source. Ministry of Finance and Planning } \\
\hline $\begin{array}{l}\text { 1/ This revision does not t } \\
\text { 2/ GST denotes general sa } \\
\text { 3/ Includes stamp duties, l }\end{array}$ & $\begin{array}{l}\text { to account the in } \\
\text { fees, and motor }\end{array}$ & $\begin{array}{l}\text { Icreases to NSL rat } \\
\text { vehicle tax. }\end{array}$ & and excise taxes & May. & & \\
\hline
\end{tabular}


Table 1 shows the various estimates throughout the year and the final outturn. The acceptance region is calculated using available data for 1993-99. Given the fact that intrayear policy changes have been quite frequent in Sri Lanka, we will use the version of the test outlined in Method 1 above. Hence we have

$$
\hat{W}_{j}=\frac{U_{j N+1}-\bar{\mu}_{j}}{\hat{\Omega}_{j}} \sqrt{\frac{N}{N+1}} \sim t_{6}
$$

where

$$
\hat{\Omega}_{j}^{2}=\frac{\sum_{t=1}^{N}\left(U_{j t}-\bar{\mu}_{j}\right)}{N-1}
$$

and the acceptance region of the test at the 5 percent level of significance is given by

$$
\bar{\mu}_{j} \pm \hat{\Omega}_{j} t_{6,0.025} \sqrt{\frac{8}{7}}
$$

Although the tests are conducted at the 5 percent level, it is also plausible to argue that a higher significance level, such as 10 percent, would be more appropriate where the test is being used as an early warning system for revenue slippage, as the cost of a type 1 error (falsely warning of a significant revenue slippage) would appear to be higher than that of a type 2 error (giving no warning, although there is a significant revenue slippage).

Alternatively, $p$-values for the test could be calculated, which has the advantage of allowing policy makers and statisticians to know the exact strength of the evidence against the null hypothesis.

The charts below display the values for $\hat{W}_{j}$, upper and lower acceptance bounds, and the estimated means $\bar{\mu}_{j}$. The vertical axis is in terms of percentage point deviation from a uniform revenue path, thus implying that the horizontal axis represents the uniform revenue path. Hence a value of $\hat{W}_{j}$ lying below the horizontal axis implies underperformance relative to the uniform path, and vice versa.

For the sake of brevity, we will focus on assessing monthly revenue outturns in relation to the revised July budget estimates (which followed the substantial revenue measures in May), and the revised October budget estimates. Notice that the budget estimates for TT/GST, excise tax, NSL, import duty, other taxes, and non-tax revenue did not change from July onward, so for these taxes we can evaluate revenue generation for all 11 months up to November. For income tax, tax revenue, and total revenue however, estimates changed in September and October, and so for completeness we also evaluate these three taxes with respect to the revised October estimates. 


\section{A. Evaluating the July Budget Estimates}

Figure 1 presents an assessment of revenue outcomes in relation to the revised July budget estimates. For each source of revenue, the relevant null hypothesis is that annual revenue generation equals the budget estimate. Note that rejection of the null hypothesis in any particular month does not preclude the possibility that the null would be accepted in a subsequent month -for example, in the case of a shortfall there could be unusually high revenue generation in subsequent months, which could make up the difference. All we can say is that rejection of the null implies that the likelihood of such revenue generation in subsequent months is very small.

Regarding the NSL, estimated mean values indicate that with the exception of January, NSL collections tend on average to be slightly below what one would expect if revenue were collected in a uniform fashion. Now looking at revenue generation through the year, we note that following a marginal rejection of the null hypothesis in February, the null hypothesis was not rejected from March through October, and in fact between July and October revenue generation improved somewhat, though still weak. However the improvement did not continue, and the null hypothesis was rejected in November.

Regarding Turnover taxes/GST (TT/GST), the monthly means are close to zero in most months, with the possible exception of September, thus suggesting that on average TT/GST revenues are collected roughly uniformly throughout the year. Looking at performance through the year, we observe that up to June the test statistic did not lie close to the lower acceptance bound. However from August revenue generation weakened, and the null hypothesis was rejected from October onward.

Regarding excise tax, the monthly means are also close to zero, though they exhibit more variability than TT/GST. Looking at performance through the year, we see that the null hypothesis was rejected from May onward, and the rejection grew stronger with each passing month.

Regarding import duty, the means tend to be below zero in every month except January, suggesting a tendency for import duty collections to be below the uniform revenue path, particularly in the middle of the year. On performance through the year, the test statistic was far from the lower acceptance bound up to May. However, after May revenue generation weakened steadily, and the null hypothesis was rejected from October onward.

Regarding income tax, we notice that the means tend to be substantially below zero in most months, and there is a lot of variability in the means, suggesting substantial divergence on average from uniform revenue generation. On performance through the year, the test statistic was close to the mean in every month up to August. However, in October revenue generation weakened, and the test statistic came close to the lower acceptance bound, though the null hypothesis was not rejected. 
Figure 1. Sri Lanka: Evaluation of July Budget Estimates

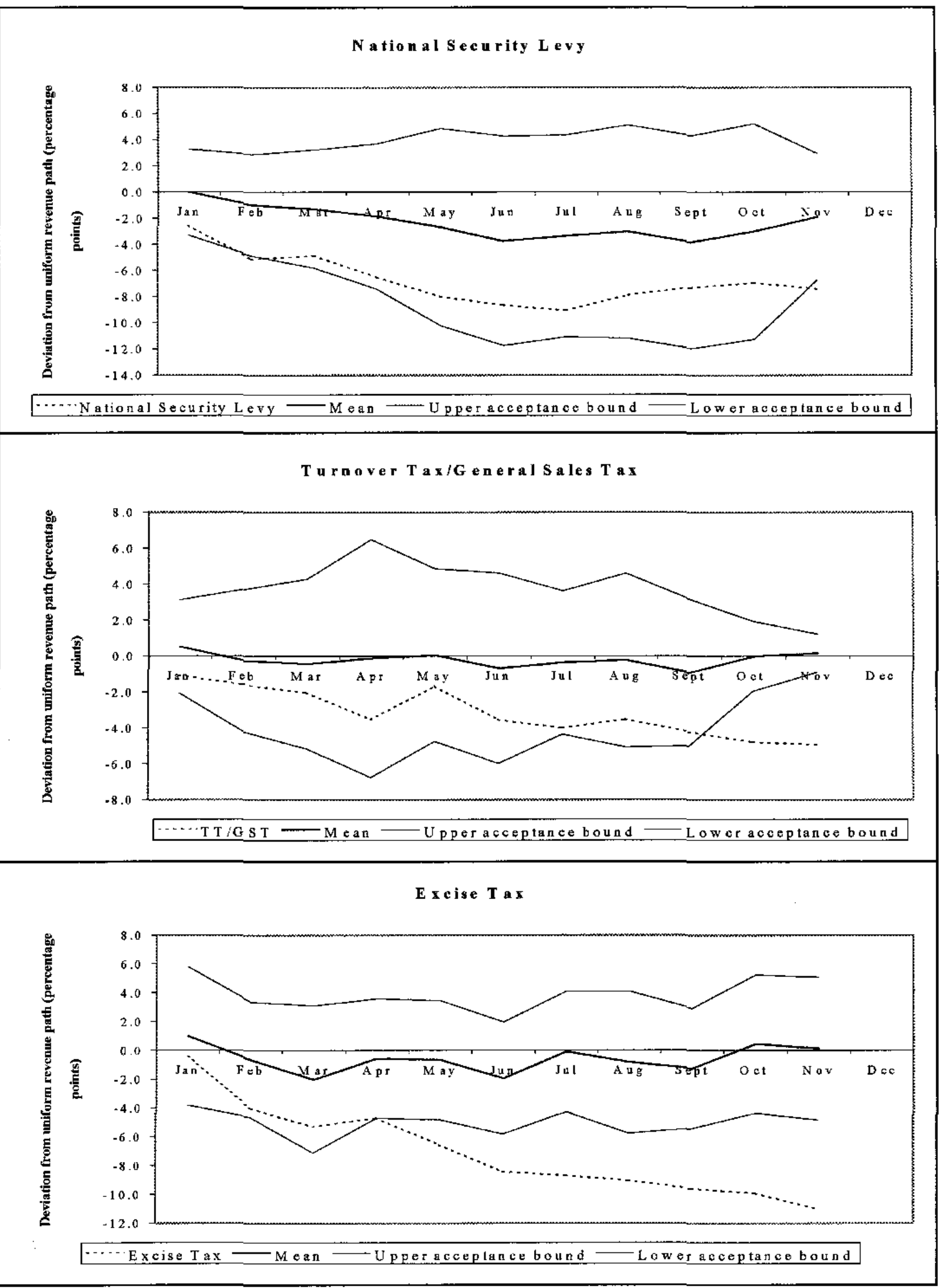


Figure 1 (continued). Sri Lanka: Evaluation of July Budget Estimates

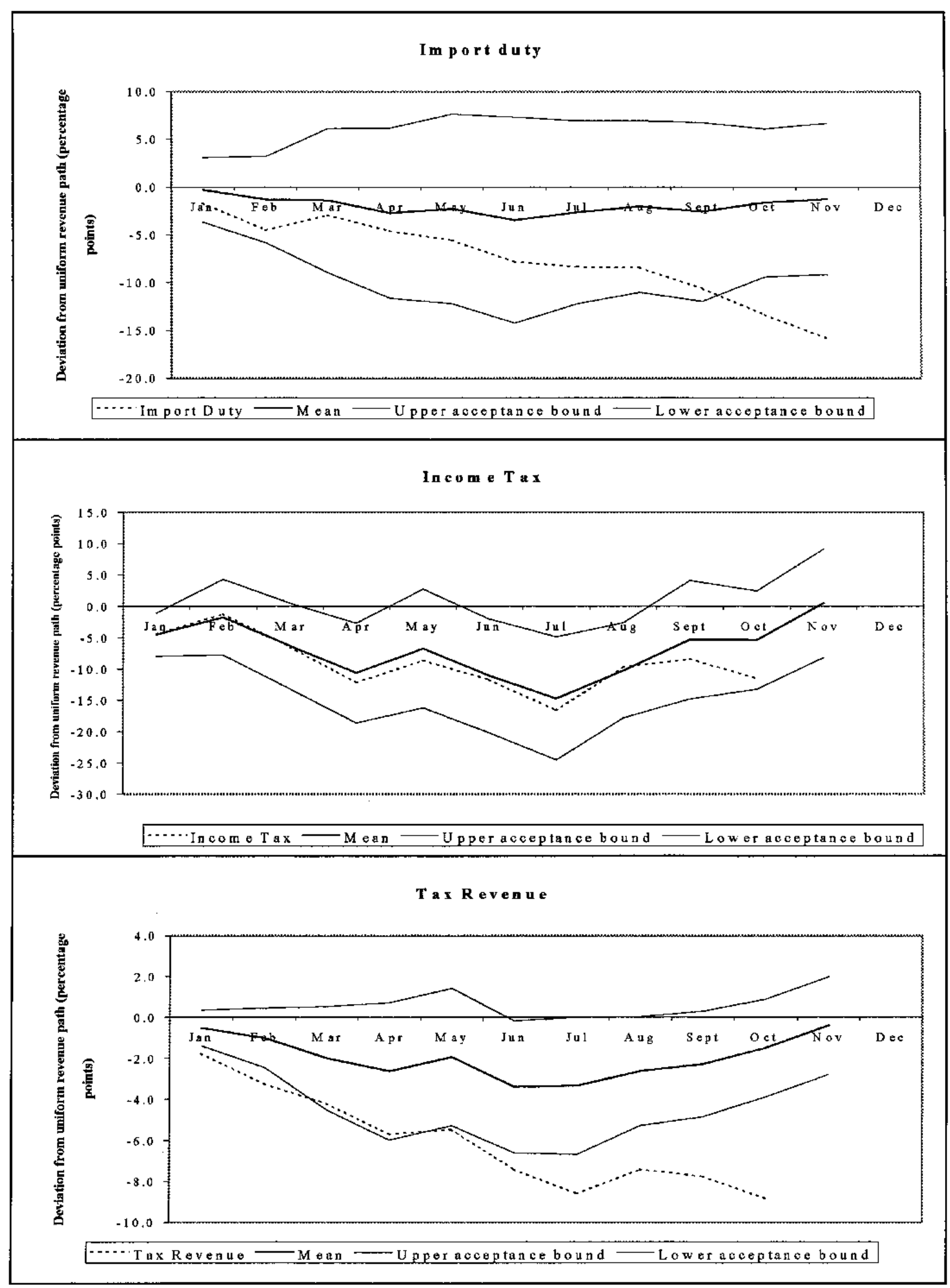


Figure 1 (concluded). Sri Lanka: Evaluation of July Budget Estimates

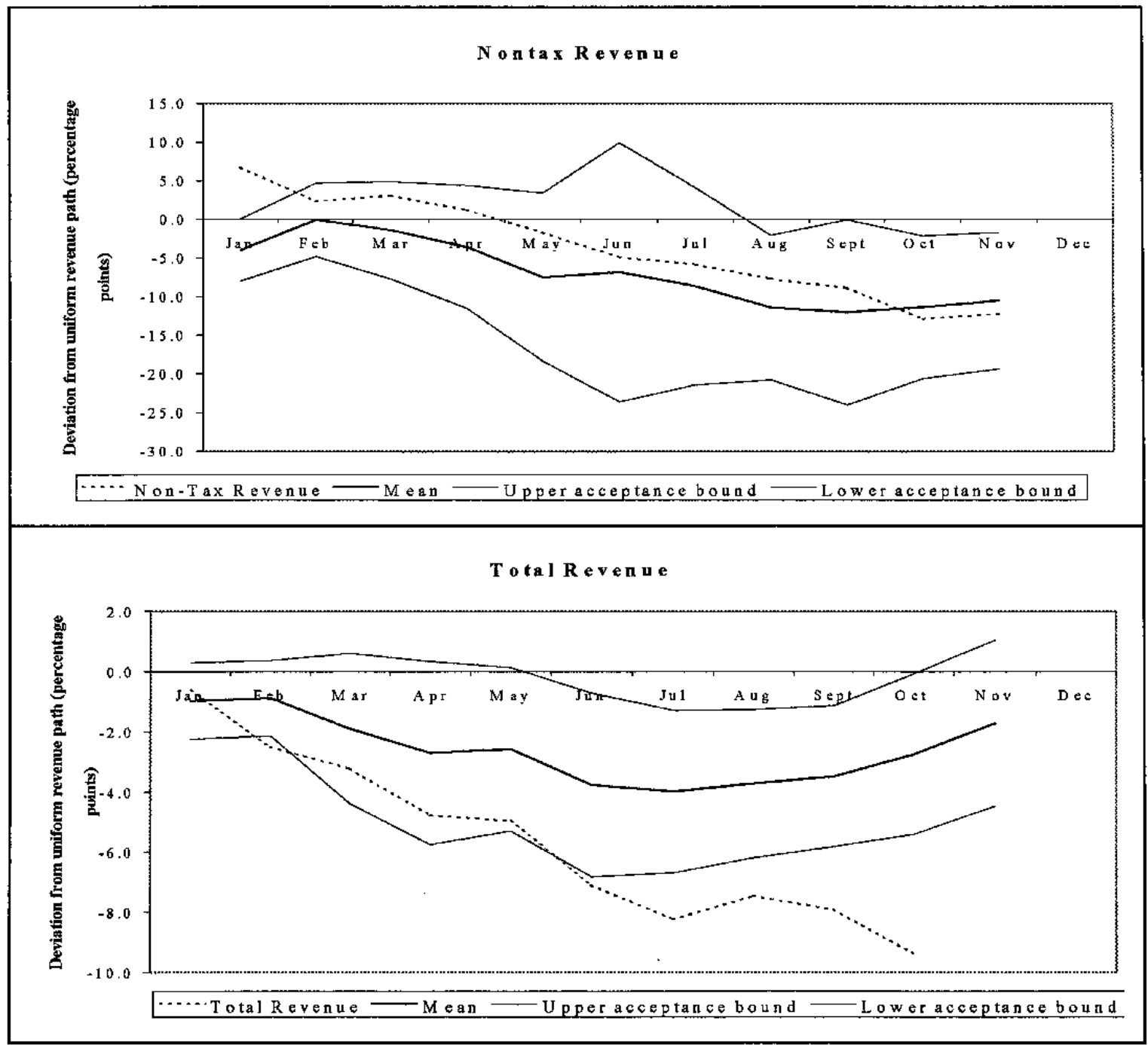

Regarding overall tax revenue, the means tend to lie well below zero, particularly in the middle of the year, suggesting that overall tax revenue tends on average to be below the uniform revenue path. On performance through the year, the test statistic was very close to the lower acceptance bound in every month, and the null hypothesis was rejected in January, and February, marginally accepted in March and April, and rejected in May. From May to October the null was rejected in every month, with the strength of the rejection increasing with every month. The weakness in overall tax revenue clearly reflected the significant shortfalls in TT/GST and excise tax.

Regarding nontax revenue, we observe that the means tend to be substantially below zero, indicating that revenue generation tends to be well below what would be expected if it were generated uniformly. On performance through the year, following a rejection of the null hypothesis in January, the test statistic lay well within the acceptance bounds-which however are rather wide - for the remainder of the year, and there was no evidence against the null hypothesis. 
Finally, for total revenue, the means tend to be substantially below zero, and are much like those for tax revenue, which is not surprising given the large share of tax revenue in total revenue. On performance, revenue generation was weak through the year, reflecting developments in tax revenue, and the null hypothesis was rejected in every month from June to October, with rejection tending to be stronger with each passing month, as the test statistic was rather close to the lower acceptance bound in every month.

\section{B. Evaluating the October Budget Estimates}

Figure 2 presents an assessment of income tax, tax revenue, and total revenue with regard to the October 31 budget estimates.

Income tax. At the new (lower) budget estimate, the test statistic remained close to the mean. Moreover, the test statistic for October was no longer close to the lower acceptance bound, in contrast to the case for the July budget estimate. As of November the test statistic was virtually zero, and was roughly equal to its mean, and there was no evidence against the October budget estimate.

Tax revenue and total revenue. The new (lower) estimates lead to a one-month delay in the onset of rejection of the null hypothesis, compared to the July budget estimates. For tax revenue, the null hypothesis was not rejected in May, but was rejected from June onward, with the rejection tending to be stronger with every passing month. Similarly, for total revenue the null hypothesis was not rejected in June, but was rejected from July onward, with the rejection tending to be stronger with every passing month. 
Figure 2. Sri Lanka: Evaluation of October Budget Estimates

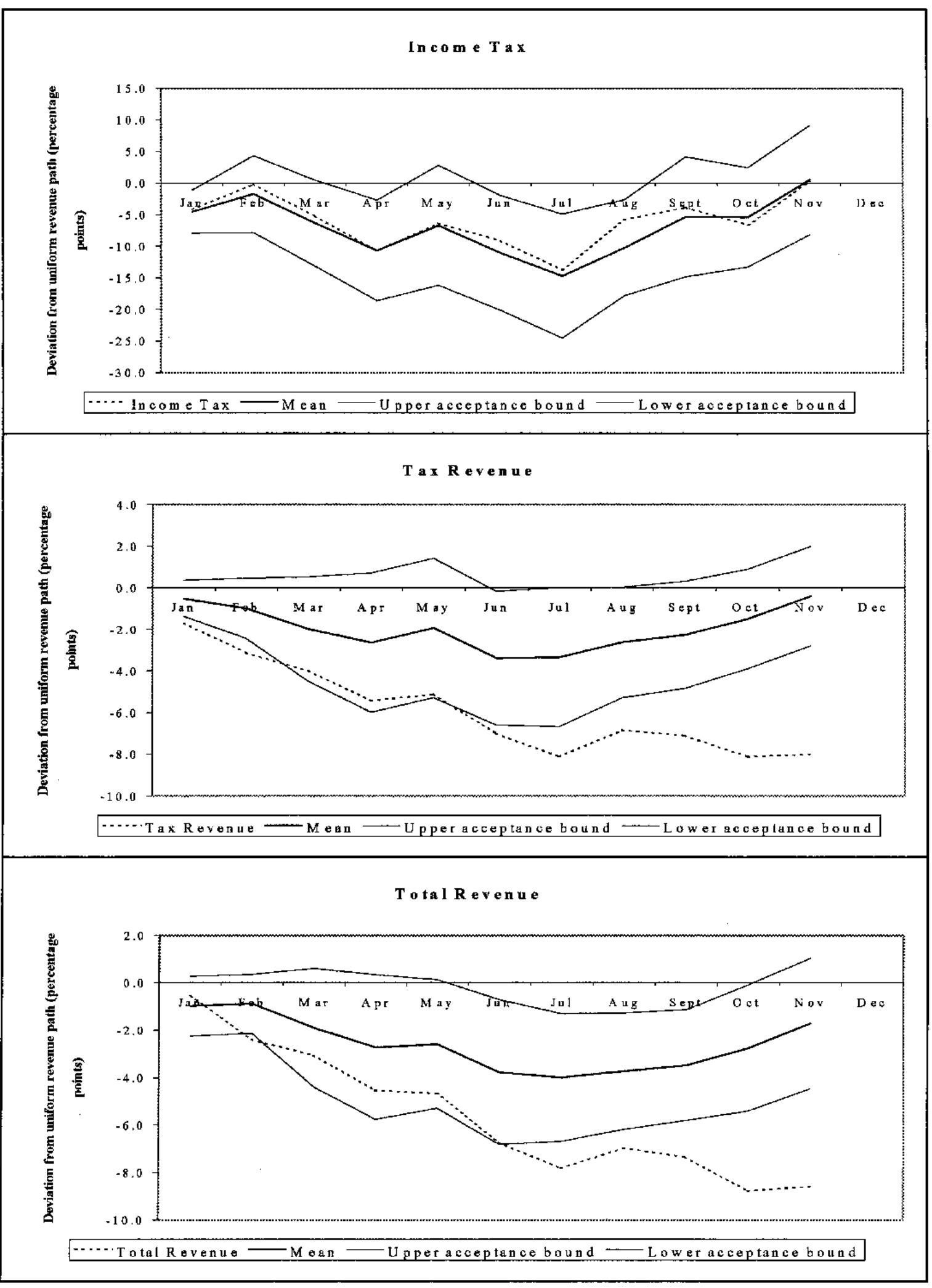




\section{EMPIRICAL RESULTS FOR THE UNITED STATES}

To demonstrate the applicability of the test to a wide variety of countries, we also evaluate US federal government budget receipt estimates for fiscal year FY2000, which runs from October 1999 to September 2000. Clearly the United States has a much larger and much more complex economy than Sri Lanka, and it is of interest to see how well the test holds up in these two very different countries.

Table 2. United States: Budget Receipts Estimates and Outturn in FY2000

\begin{tabular}{|lrr|}
\hline & Budget & Outturn \\
\hline Total Receipts 1/ & 1,956 & 2,025 \\
Individual Income Tax & 952 & 1,005 \\
Corporation Income Tax & 192 & 207 \\
Social Insurance and Retirement & 650 & 653 \\
Excise Taxes & 68 & 69 \\
Estate and Gift Taxes & 31 & 29 \\
Customs Duties & 21 & 20 \\
Miscellaneous & 43 & 43 \\
\hline Source. Office of Management and Budget & & \\
1/ In billions of dollars. & & \\
\hline
\end{tabular}

The budget estimates for FY 2000 receipts we use are those released in February 2000 as part of the basis for the FY 2001 budget proposals presented to Congress. Thus the projections of annual receipts have had the advantage of being fine-tuned based on actuals for about 4 months of FY 2000, and as such forecast errors are likely to be small, thus providing a rigorous challenge for the test's power. Table 2 presents budget estimates for FY 2000 and the actual outturn. As we can see, while total receipts and income tax outturns clearly differed from the budget estimates, budget estimates and outturns for the other receipts were generally extremely close to each other, and it is of interest to see how well the model performs in predicting these outcomes.

Figure 3 presents the assessment of receipt outcomes. As described above, for each source of receipts the relevant null hypothesis is that the outturn for FY2000 equals the budget estimate. Overall, test power appears to be good, as can be seen from examination of the individual charts.

The acceptance region is calculated using data from FY 1969 to FY1999, thus yielding a sample of size 31 . As a result, the test statistic has a $t$ distribution with 30 degrees of freedom, and the acceptance region at the 5 percent significance level is given by: 


$$
\bar{\mu}_{j} \pm \hat{\Omega}_{j} t_{30,0.025} \sqrt{\frac{32}{31}}
$$

As it would be extremely tedious to attempt to identify the exact details of all intra-year policy changes over the sample period, we will use the version of the model outlined in Method 1 above.

Total receipts. Here, estimated monthly mean values all lie below zero, thus indicating that on average total receipts tend to be below what one would expect if receipts were generated in a uniform fashion. Looking at receipts performance throughout the year, we see that up to April the test statistic was within the acceptance bounds, indicating that performance was essentially on track. However, from May onward strong receipts caused a rejection of the null hypothesis, with significant evidence that the budget estimate would be exceeded.

Individual income tax. Here also the estimated means tend to lie below zero, with the exception of January and April. Overall we would conclude that income tax receipts tend to be lower than the uniform generation path with the exception of these two months. Performance through the year was similar to that for total revenue, which is not surprising given the large share of revenue from this source. Thus from May onward strong receipts caused a rejection of the null hypothesis, with significant evidence that the budget estimate would be exceeded.

Corporation income tax. Here, estimated monthly mean values all lie below zero, with the exception of June, and they exhibit a substantial amount of variability. The acceptance region is rather wide, particularly in the latter part of the year, suggesting that test power is unlikely to be very high. On average receipts tend to be well below what one would expect if receipts were generated in a uniform fashion. Looking at receipts performance throughout the year, we see that the test statistic was generally well within the acceptance bounds, and there was no significant evidence against the null hypothesis throughout the year, although the test statistic lay above the mean for most of the year.

Social insurance and retirement. Here, estimated monthly mean values all lie below zero, with the exception of August, and there is a clear tendency for receipts to be well below the uniform generation path from November through April. Looking at receipts performance throughout the year, we see that the test statistic lay above the mean in every month, and from May onward receipts exceeded what would be expected under the uniform path. However, there was no significant evidence to suggest that the annual target would be exceeded, notwithstanding the strong performance.

Excise taxes. Here, estimated monthly mean values all lie close to the horizontal axis, suggesting that on average receipts tend not to stray too far from the uniform path. On receipts performance, we see that the test statistic was well within the acceptance bounds throughout the year, although performance was relatively weak, as it lay below the mean. 
Figure 3. United States: Evaluation of Budget Estimates

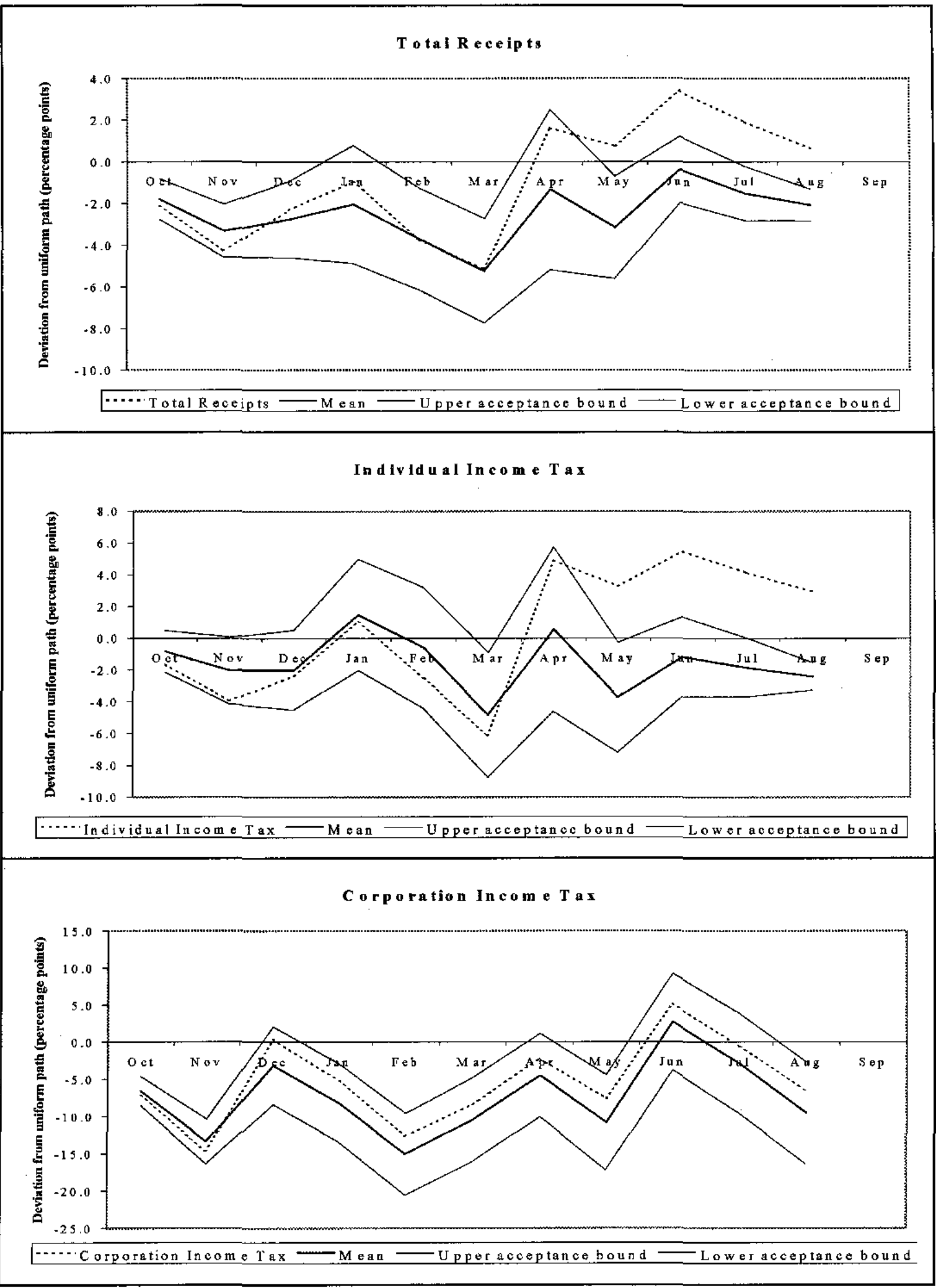


Figure 3 (continued). United States: Evaluation of Budget Estimates

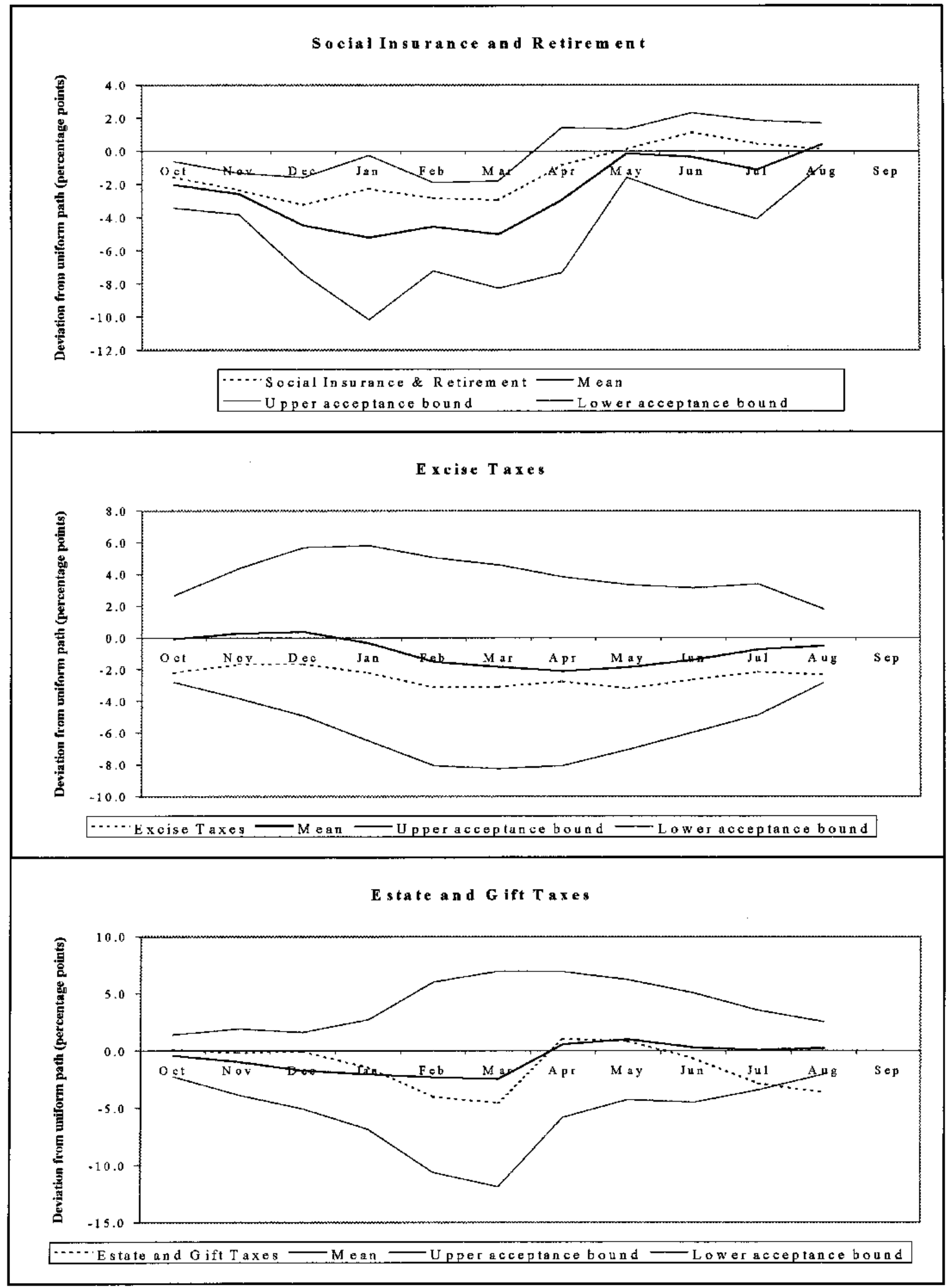


Figure 3 (concluded). United States: Evaluation of Budget Estimates

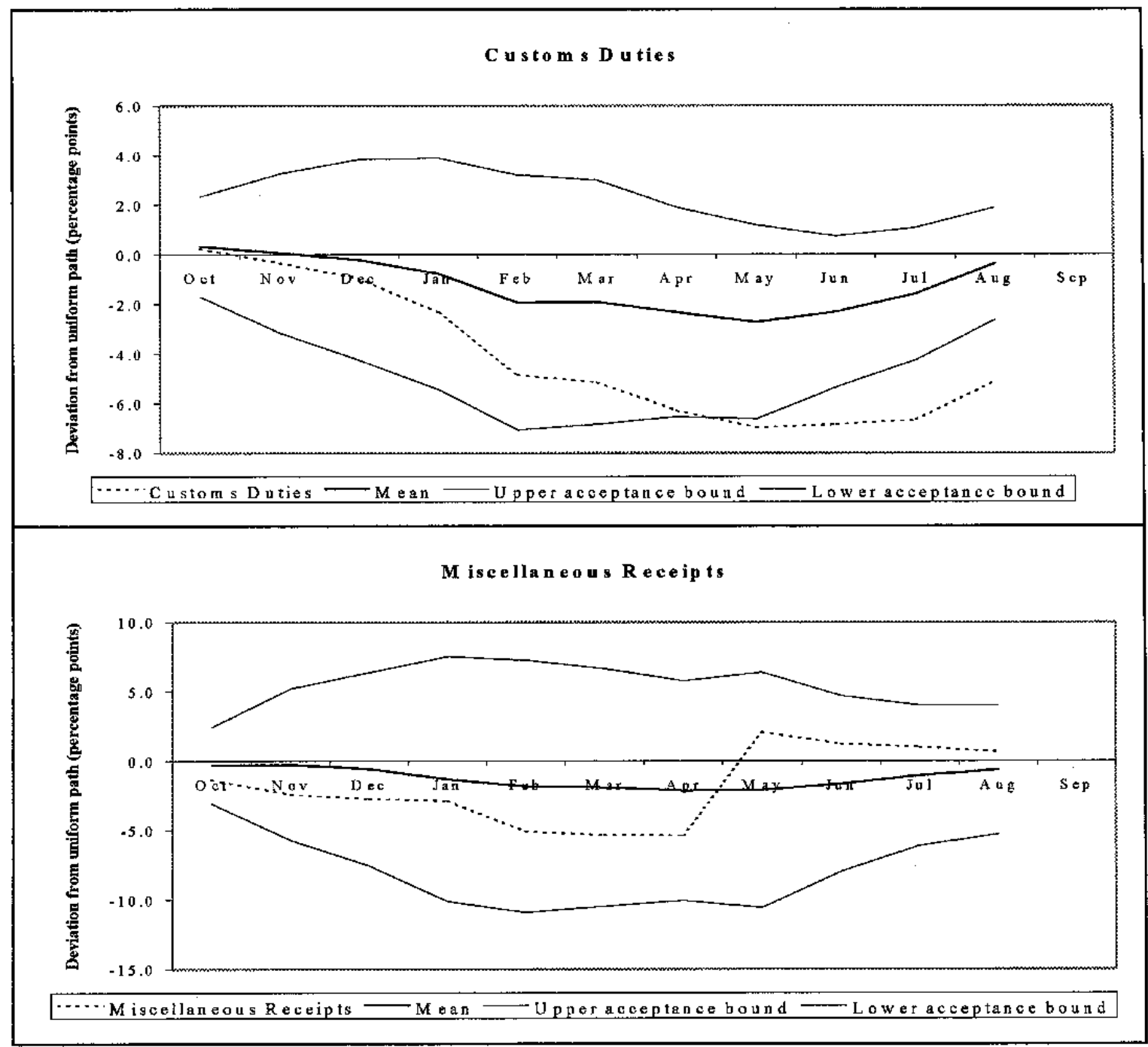

Estate and gift taxes. Here, estimated monthly mean values all lie close to the horizontal axis, suggesting that on average receipts tend not to stray too far from the uniform path. However, there is a slight tendency for receipts to underperform relative to the uniform path up to March. On receipts performance, we see that the test statistic was well within the acceptance region up to June. However, there was evidence of weakening performance in July, and the null hypothesis was rejected in August.

Customs duties. Here, estimated monthly mean values tend to lie below zero from December through August, suggesting that on average receipts tend to lie below the uniform path. On receipts performance, we see that from November onward the test statistic steadily declined, signaling continuously weakening receipts, and the null hypothesis was rejected from May onward.

Miscellaneous receipts. Here, estimated monthly mean values tend to be close to zero throughout the year, suggesting that on average receipts tend to be generated in a uniform 
fashion. On receipts performance, the test statistic lay well within the acceptance bounds throughout the year, thus indicating no significant evidence against the null hypothesis.

\section{ConCluding Remarks}

This paper develops a statistical framework for evaluating monthly progress toward annual revenue targets, and applies it to Sri Lankan and United States data.

Comparing our inferences with the actual annual outturns, we observe that for Sri Lanka the tests correctly predicted the shortfalls in the NSL, TT/GST, excise tax, overall tax revenue, and total revenue. However, test power was not 100 percent, and so we were not able to detect the (small) underperformance in income tax or the larger slippage in non-tax revenue. Test power appears to be weakest in the case of nontax revenue, as can be seen from the fact that the acceptance region in this case tends to be very wide. This probably reflects the fact that non-tax revenue is the one revenue source most likely to be subject to significant and frequent intra-year policy changes.

For the United States case, the test correctly predicted the overperformance in total receipts and individual income tax, and the underperformance in estate and gift taxes, and customs duties. It also correctly predicted that miscellaneous receipts would be on target. Unsurprisingly, however, the very small discrepancies between budget targets and outturns for social insurance and retirement and excise tax receipts were not predicted--in most statistical tests test power tends to decline as the null hypothesis gets closer to the true data generating process. Test power was weakest in the case of corporation income tax, where the relatively substantial overperformance was not predicted as a result of the very wide acceptance region.

Overall, test power appears to be quite high in both countries, and this framework is a promising tool for evaluating annual targets in light of monthly outturns. A further advantage of the test is that different sample sizes are automatically taken into consideration with no problems--this was indicated by the theoretical results, and was borne out by the fact that the test was implemented successfully for both the Sri Lanka case with a sample size of 7 and the United States case with a sample size of 31 . However, this result depends on the normality assumption for the random term in equation (1). In practice, this should not be a serious problem, because the random element in equation (1) is essentially the error term after all the important determining variables have been taken into account, and it should therefore be close to a zero-mean, symmetrical, white noise variable. As such its distribution is unlikely to be far from normal. However, where there is reason to believe that the error terms are far from normally distributed, one possible approach would be to use Monte Carlo methods to derive close approximations to the actual distribution of the test statistic. 


\section{Conditions for Exact Aggregation}

We have the model

$$
x_{q i t}=\alpha_{q i} X_{q}\left(T_{q t}\right)+\varepsilon_{q i t}
$$

where $q=1, \ldots Q, i=1, \ldots 12$, and $t=1, \ldots N$ refer to tax type, month of year, and year, respectively. It is assumed that $\varepsilon_{q i t}$ is distributed $N\left(0, \sigma_{q i t}^{2}\right), \sigma_{q i t}^{2}=\sigma_{q i}^{2} X_{q}\left(T_{q t}\right)^{2}$ and $\operatorname{cov}\left(\varepsilon_{q i t}, \varepsilon_{q k t}\right)=\sigma_{q i k} X_{q}\left(T_{q t}\right)^{2}$.

Then aggregate revenue in a particular month is given by

$$
Z_{i t}=\sum_{q=1}^{Q} x_{q i t}
$$

and total revenue for the year would be given by

$$
T R_{t}=\sum_{q=1}^{Q} X_{q}\left(T_{q t}\right)
$$

We wish to establish that conditions 1 and 2 below are sufficient to enable us to write the data generating process for $Z_{i t}$ as

$$
Z_{i t}=\delta_{i} T R_{t}+v_{i t}
$$

where $v_{i t}$ is distributed $N\left(0, \psi_{i t}^{2}\right), \psi_{i t}^{2}=\psi_{i}^{2} T R_{t}^{2}$, and $\operatorname{cov}\left(v_{i t}, v_{k t}\right)=\psi_{i k} T R_{t}^{2}$.

Condition 1. $X_{q}\left(T_{q t}\right)=\tau_{q} T R_{t}$ where $\tau_{q}$ are constant and $\sum_{q=1}^{Q} \tau_{q}=1$, for all $t$. In other words, the shares of various taxes in total revenue are constant.

Condition 2. $\operatorname{cov}\left(\varepsilon_{\text {qit }}, \varepsilon_{\text {sht }}\right)=0$ for all $q \neq s$. In other words, error terms from different tax types are independent. ${ }^{6}$

\footnotetext{
${ }^{6}$ Aggregation will also hold exactly if we assume instead that the covariances can be expressed $\operatorname{as} \operatorname{cov}\left(\varepsilon_{q i t}, \varepsilon_{s i t}\right)=X_{q}\left(T_{q t}\right) X_{s}\left(T_{s t}\right) \delta_{q s}$, where $\delta_{q s}$ is a constant.
} 
Taking the first expression on the right-hand side of equation (1), and substituting condition 1 we have:

$$
\sum_{q=1}^{Q} \alpha_{q i} X_{q}\left(T_{q t}\right)=T R \sum_{q=1}^{Q} \alpha_{q i} \tau_{q}=\delta_{i} T R_{t}
$$

Taking the second expression on the right-hand side of equation (1) and using both conditions 1 and 2, we have:

1. Let $v_{i t}=\sum_{q=1}^{Q} \varepsilon_{q i t}$. Then $E\left(v_{i t}\right)=0$, and $v_{i t}$ is clearly normally distributed.

2. Calculating the variance of $v_{i t}$,

$$
\begin{aligned}
\operatorname{Var}\left(v_{i t}\right) & =\sum_{q=1}^{Q} \sigma_{q i}^{2}\left(X_{q}\left(T_{q t}\right)\right)^{2}+2 \operatorname{cov} \sum_{1 \leq q<s<Q} \sum \operatorname{cov}\left(\varepsilon_{q i t}, \varepsilon_{s i t}\right) \\
& =\sum_{q=1}^{Q} \sigma_{q i}^{2}\left(X_{q}\left(T_{q t}\right)\right)^{2} \\
& =T R_{t}^{2} \sum_{q=1}^{Q} \sigma_{q i}^{2} \tau_{q}^{2} \\
& =\psi_{i}^{2} T R_{t}^{2}
\end{aligned}
$$

3. Finally, calculating the covariance terms,

$$
\begin{aligned}
\operatorname{cov}\left(v_{i t}, v_{k t}\right) & =E\left[\left(\varepsilon_{1 i t}+\ldots .+\varepsilon_{q i t}\right)\left(\varepsilon_{1 k t}+\ldots .+\varepsilon_{q k t}\right)\right] \\
& =E\left[\varepsilon_{1 i t} \varepsilon_{1 k t}+\ldots+\varepsilon_{q i t} \varepsilon_{q k t}\right] \\
& =\sum_{q=1}^{Q} \sigma_{q i k}\left(X_{q}\left(T_{q t}\right)\right)^{2} \\
& =T R_{t}^{2} \sum_{q=1}^{Q} \sigma_{q i k} \tau_{q}^{2} \\
& =T R_{t}^{2} \psi_{i k}
\end{aligned}
$$




\section{Bibliography}

Central Bank of Sri Lanka, Annual Report, 1993-2000, (Colombo).

Davidson, Russell, and James G. Mackinnon, 1993, Estimation and Inference in Econometrics, (Oxford University Press).

Roussas, George, 1997, A Course in Mathematical Statistics, $2^{\text {nd }}$ ed. (New York: Academic Press).

United States, Office of Management and Budget, Budget of the United States Government, Fiscal Years 2000 and 2001. 